\title{
Prevalences of ECG findings in large population based samples of men and women
}

\author{
D De Bacquer, G De Backer, M Kornitzer
}

\begin{abstract}
Objective-To obtain accurate estimates of the prevalence of ECG abnormalities in the general population and to describe them in relation to age, sex, and some lifestyle related factors.

Design-The results were obtained from the records of 47358 men and women participating in four large Belgian epidemiological studies during the past 30 years. All tracings were read and coded by two trained cardiologists on the basis of Minnesota code criteria.

Results-Prevalences of coronary heart disease and abnormal ECG findings rose exponentially with age in both sexes, with the exception of atrioventricular block and the Wolff-ParkinsonWhite (WPW) syndrome. Major ECG findings were observed in $6.0 \%$ of all men and $4.3 \%$ of women, resulting in a significant adjusted sex ratio of 1.66 (95\% confidence interval 1.46 to 1.88). The prevalence of minor ECG changes was slightly higher among men $(10.4 \% v 9.5 \%$ in women). The occurrence of ischaemia-like findings on the ECG was comparable between men and women $(9.0 \% v 9.8 \%)$. Independent of age, smoking, obesity, diabetes, employment status, positive history of angina or infarction, and region, there were significantly higher prevalences of $\mathrm{Q} / \mathrm{QS}$ patterns, left ventricular hypertrophy, left axis deviation, arrhythmias, and atrial fibrillation or flutter in men than in women. Right bundle branch block and WPW syndrome both occurred 3.5 times more often in men, while the prevalence of left bundle branch block was comparable between the sexes.

Conclusions-The large sample size allowed a precise description of the most important ECG abnormalities. These are not rare in the adult population and most are strongly age related. Sex differences occur with some, but not all, abnormalities. The less common ECG abnormalities were more often observed among men.
\end{abstract}

(Heart 2000;84:625-633)

Keywords: ECG abnormalities; Minnesota code

In cardiac medicine, the resting ECG has proved its value as a diagnostic tool for detecting heart disease. ${ }^{12}$ Apart from its use in the clinical context, the ECG has been employed as a prognostic tool in apparently healthy subjects. ${ }^{3-15}$ From Bayes' theorem, the intrinsic value of the ECG as a valuable diagnostic tool is dependent on the prevalence the findings in the general population. Therefore accurate estimates of the "true" prevalences of ECG abnormalities from large samples are central to the interpretation of the predictive value of ECG findings. Since the introduction of the Minnesota code, ${ }^{16}{ }^{17}$ several epidemiological studies have concentrated on estimating the prevalences of ECG abnormalities in a standardised way. ${ }^{18-24}$ However, most of these studies were based on population samples of men, and only a few reports contained data on women. The objective of our study was to obtain accurate estimates of the prevalences of ECG changes in the general population and to describe these prevalences in relation to age, sex, and some lifestyle factors. In contrast to previous reports from large studies where study populations were highly selective, such as life insurance candidates and air force personnel, ${ }^{24}$ our results are derived from community based cohorts.

\section{Methods}

STUDY POPULATIONS

Our results are based on data derived from four large epidemiological studies performed in
Belgium during the past 30 years. The results reported here were obtained from the records of 47358 subjects (34 731 men; 12637 women) who participated in these studies.

The Belgian heart disease prevention project (BHDPP), ${ }^{25}$ which was part of the World Health Organization European collaborative trial, ${ }^{26}$ was a multifactorial randomised controlled trial of primary prevention of cardiovascular diseases in a population of working men. The data used in this analysis are those obtained at the final examination in men aged 40-64 years collected in the period 1978-80. Information was obtained by validated self administered questionnaires, clinical examination, and a standardised ECG. The participation rate in the BHDPP study was $71 \%$. In all, 10064 records with complete ECG information from the BHDPP study population were used in the present analyses.

In contrast to the BHDPP study of working men, the Belgian interuniversity research on nutrition and health (BIRNH) study was a population based survey designed to study the association between nutritional patterns, clinical and biochemical characteristics, and total and cause specific mortality in men and women. ${ }^{27} \mathrm{~A}$ random age and sex stratified sample was selected from voting lists in 42 of the 43 administrative districts in Belgium. The participation rate in this population based study was $36 \%$. Baseline data were gathered in the period 1980-84, and included self adminis- 
tered questionnaires, clinical examinations, and a standardised ECG, adopting similar methodology, questionnaires, and equipment to those used in the BHDPP study. Data on 5816 men and 5215 women aged $25-74$ years were available for analysis.

The MONICA (monitoring trends and determinants in cardiovascular disease) project is also a population based study, concentrating on the trends in both incidence and risk factors of cardiovascular diseases. ${ }^{28}$ The Belgian collaborating MONICA centre, Ghent-Charleroi, carried out three independent risk factor surveys (1985-86, 1988-89, and 1990-92) in the general population. ${ }^{29}$ For each survey, an age and sex stratified random sample of 2000 subjects aged 25-64 years was selected in the cities of Ghent and Charleroi. Combining the three surveys, the participation rates were $53 \%$ in Ghent and $37 \%$ in Charleroi. All medical examinations, including an ECG, were performed according to the MONICA protocol. Records from 2529 men and 2344 women aged 25-64 years were found suitable for inclusion in these analyses.

Finally, the Belgian jobstress project (BELSTRESS $)^{30}$ is a large scale multidisciplinary study dealing with the independent relation of perceived job stress to the incidence of fatal and non-fatal coronary heart disease. The initial sample consists of middle aged men and women (35-59 years) at work in large Belgian industries. The participation rate was $48 \%$. From the baseline screening (1994-98), ECG data on 21390 people (16 312 men, 5078 women) were available for our data analyses.

DEFINITIONS OF LIFESTYLE CHARACTERISTICS AND CORONARY HEART DISEASE

All the variables considered in the present analysis were defined consistently in all four studies. Age was defined as the subject's age at the time of medical examination. Smoking was defined as current cigarette smoking. Body mass index (BMI) was calculated as the weight $(\mathrm{kg})$ divided by height squared $\left(\mathrm{m}^{2}\right)$. In relation to lifestyle and cultural differences, regional comparisons were made between north and south Belgium. The impact of employment status was investigated by comparing subjects in regular employment with those not in regular employment. Hypertension was defined according to the WHO definition as "systolic blood pressure $\geqslant 140 \mathrm{~mm} \mathrm{Hg}$, and/or diastolic blood pressure $\geqslant 90 \mathrm{~mm} \mathrm{Hg}$, and/or currently under antihypertensive drug treatment". A high blood cholesterol concentration was defined as a total cholesterol $\geqslant 250 \mathrm{mg} / \mathrm{dl}$ $(6.48 \mathrm{mmol} / \mathrm{l})$. Information on angina pectoris was obtained by following the Rose questionnaire ${ }^{31}$ while a history of acute myocardial infarction was self reported. Coronary heart disease was defined as angina pectoris or a positive history of acute myocardial infarction, or having $\mathrm{Q}$ wave evidence of an old myocardial infarct on the resting ECG (Minnesota codes $\mathrm{I}_{1,2}$ ).
RESTING ECG

A 12 lead ECG was taken in the supine position in accordance with classical recommendations in all four studies. All tracings from the BHDPP, BIRNH, and MONICA studies were read by a trained cardiologist (MK). The ECG reading in the BELSTRESS study was done by two cardiologists (MK and GDB). All ECGs were coded on the basis of the Minnesota coding criteria. ${ }^{17}$ In order to obtain groups sufficiently large to allow reliable conclusions, ECG findings were further pooled using several classifications. According to the criteria of the pooling project, ${ }^{32}$ major ECG abnormalities consist of ST segment depression (Minnesota codes $\mathrm{IV}_{1-2}$ ), $\mathrm{T}$ wave inversion (codes $\mathrm{V}_{1-2}$ ), complete or second degree atrioventricular (AV) block (codes $\mathrm{VI}_{1-2}$ ), complete left or right bundle branch block (codes VII $_{1-2}$ ), frequent premature beats (code $\mathrm{VIII}_{1}$ ), and atrial fibrillation or flutter (code $\mathrm{VIII}_{3}$ ). Minor ECG abnormalities include borderline $\mathrm{Q}$ wave (code $\mathrm{I}_{3}$ ), left or right axis deviation (codes $\mathrm{II}_{1-2}$ ), QRS high voltage (codes III $_{1-2}$ ), borderline ST segment depression (code $\mathrm{IV}_{3}$ ), $\mathrm{T}$ wave flattening (code $\mathrm{V}_{3}$ ), and QRS low voltage (code IX ). $_{1}$. As a relatively high proportion of the subjects with minor abnormalities also showed signs of major ECG changes (11\% in both sexes), the presence of isolated minor abnormalities was also assessed. Signs suggesting myocardial ischaemia ("ischaemic ECG") were defined as the presence of $\mathrm{Q} / \mathrm{QS}$ patterns (code $\mathrm{I}_{1-3}$ ), significant or borderline ST segment depression (codes $\mathrm{IV}_{1-3}$ ), deep or moderate $\mathrm{T}$ wave inversion (codes $\mathrm{V}_{1-3}$ ), or evidence of complete left bundle branch block (code $\mathrm{VII}_{1}$ ). Finally, separate analyses were performed for $\mathrm{Q} / \mathrm{QS}$ patterns (codes $\mathrm{I}_{1-3}$ ), left axis deviation (code II $_{1}$ ), high R waves (code III $_{1}$ ), ST depression (codes $\mathrm{IV}_{1-3}$ ), abnormal $\mathrm{T}$ wave (codes $\mathrm{V}_{1-3}$ ), AV block (codes $\mathrm{VI}_{1-2,4}$ ), Wolff-ParkinsonWhite syndrome (code $\mathrm{VI}_{4}$ ), left bundle branch block (code $\mathrm{VII}_{1}$ ), right bundle branch block (code $\mathrm{VII}_{2}$ ), any bundle branch block (codes $\mathrm{VII}_{1-2,4}$ ), arrhythmias (codes $\mathrm{VIII}_{1-6}$ ), atrial fibrillation or flutter (code $\mathrm{VIII}_{3}$ ), and a combination of arrhythmias or AV block (codes VIII $_{1-6}$ or codes $\mathrm{VI}_{1-2,4}$ ). Left ventricular hypertrophy was defined as the joint occurrence of an isolated hypertrophy (code $\mathrm{III}_{1}$ ) in combination with either ST depression (codes $\mathrm{IV}_{1-3}$ ) or a $\mathrm{T}$ wave change (codes $\mathrm{V}_{1-3}$ ).

\section{STATISTICAL METHODS}

The differences in age distribution between the four studies justified the need for age standardisation in reporting study specific results. This standardisation was done by the direct method $^{33}$ using five year and 10 year age strata, and with the male and female Belgian population of 1 January 1995 as reference. The potential synergistic effect of age and sex on the prevalence of ECG changes was evaluated statistically using interaction testing within the framework of a multiplicative logistic model. The associations between lifestyle related factors and all ECG classifications were expressed by odds ratios. To estimate the precision and significance of these odds ratios, 
Table 1 Distribution of age by study and sex

\begin{tabular}{llllll}
\hline & $\begin{array}{l}\text { BHDPP } \\
(n=10 \text { 064) }\end{array}$ & $\begin{array}{l}\text { BIRNH } \\
(n=11 \text { 031 })\end{array}$ & $\begin{array}{l}\text { MONICA } \\
(n=4873)\end{array}$ & $\begin{array}{l}\text { BELSTRESS } \\
(n=21 \text { 390 })\end{array}$ & $\begin{array}{l}\text { Total sample } \\
(n=47358)\end{array}$ \\
\hline $\begin{array}{lllll}\text { Men } \\
\text { 25-34 years }\end{array}$ & - & & & & 1620 \\
35-44 years & 1780 & 1042 & 578 & - & 10234 \\
45-54 years & 6215 & 1254 & 580 & 6520 & 16584 \\
55-64 years & 2069 & 1262 & 636 & 8471 & 5321 \\
65-74 years & - & 1292 & 635 & 1321 & 962 \\
Total & 10064 & 962 & - & - & 34731 \\
& 5816 & 2529 & 16312 & \\
Women & & & & & 1497 \\
25-34 years & - & 1948 & 549 & - & 3588 \\
35-44 years & - & 1224 & 625 & 2739 & 1903 \\
45-54 years & - & 1244 & 599 & 2088 & 718 \\
55-64 years & - & 1081 & 571 & 251 & 12637 \\
65-74 years & - & 718 & - & - & \\
Total & - & 5215 & 2344 & 5078 & \\
\hline
\end{tabular}

BELSTRESS, Belgian jobstress project; BHDPP, Belgian heart disease prevention project; BIRNH, Belgian interuniversity research on nutrition and health study; MONICA, monitoring trends and determinants in cardiovascular disease.

$95 \%$ confidence intervals are given. Odds ratios were multivariately adjusted using logistic regression analysis. All statistical analyses were performed with SAS software. ${ }^{34}$ A level of $\alpha=0.05$ was used to indicate significance. The Wald $\chi^{2}$ test for interaction was performed with a significance level of $\alpha=0.01$.

\section{Results}

The distribution of age in the two sexes is given in table 1 . Most of the subjects in the study population were aged $35-54$ years. In table 2 prevalences of lifestyle related characteristics and coronary heart disease are given for the male and female subjects aged $40-59$ years, the common age group in all four studies. As expected, smoking rates in men showed a decrease over time, while the rates for women were increasing. In men, the prevalence of obesity (BMI $\geqslant 30 \mathrm{~kg} / \mathrm{m}^{2}$ ) seems to be increasing, while in women it remains high. The French speaking community was less represented in the BHDPP and BIRNH studies than in MONICA and BELSTRESS. With respect to risk factors for coronary heart disease, decreasing rates were observed for hypertension and hyperlipidaemia, while the prevalence of overt coronary heart disease appeared to be on the increase in women. Obviously, in the interpretation of these trends one should take into account a possible selection bias because the BHDPP and BELSTRESS studies were performed in working populations only.

Pooling all four studies provides a powerful database that allows the study of prevalences of coronary heart disease and abnormal ECG findings as a function of age and sex. As can be seen in table 3, all of these prevalences rose exponentially with age in both sexes, with the exception of AV block and the WolffParkinson-White syndrome. In men the prevalence of high $\mathrm{R}$ waves (Minnesota code $\mathrm{III}_{1}$ ) showed a curvilinear association with age, the prevalences in young men being comparable with those aged over 65 years. This ECG finding seems to decrease with age until around 55 years, after which it increases again in the older age groups.

Fitting the appropriate interaction term in a multiplicative model showed a significant effect modification by sex in the relation between age and the prevalence of coronary heart disease, ECG changes of angina pectoris, overt coronary heart disease, and high $\mathrm{R}$ waves. The age standardised prevalences of coronary heart disease and abnormal ECG findings are also given in table 3 for men and women, together with the age adjusted sex ratio. In our combined sample of four large datasets, overt coronary heart disease was found in $8.3 \%$ of men and $7.6 \%$ of women. In subjects under 55 years of age, however, the prevalence was higher in women, the situation being reversed at higher ages. Major ECG findings were observed in $6.0 \%$ of all men and in $4.3 \%$ of women, resulting in a significant age adjusted sex ratio of 1.42 . The prevalence of minor ECG changes was only slightly higher among men $(10.4 \%$ v $9.5 \%$ in women) with a significant relative increase of $13 \%$. Ischaemia-like findings on the ECG were less prevalent among men than among women $(9.0 \% v 9.8 \%)$. Furthermore, independent of age, significantly higher prevalences in men were found for $\mathrm{Q} / \mathrm{QS}$ patterns, left ventricular hypertrophy, left axis deviation, bundle branch block, WolffParkinson-White syndrome, and atrial fibrillation or flutter. The higher prevalence of bundle branch block seemed to be explained mainly by the higher prevalence of right bundle branch block, which occurred 3.5 times more often in men than in women. In contrast, the prevalence of left bundle branch block was comparable between the sexes. Women had significantly more ST changes $(2.6 \% v 2.3 \%$ in men $)$ and $\mathrm{T}$ wave abnormalities ( $7.6 \% v 6.5 \%$ in men) on the resting ECG.

Table 2 Age standardised prevalences of lifestyle characteristics and coronary heart disease in 40-59 year old men and women

\begin{tabular}{|c|c|c|c|c|c|c|c|}
\hline & \multicolumn{4}{|l|}{ Men } & \multicolumn{3}{|l|}{ Women } \\
\hline & $\begin{array}{l}\text { BHDPP } \\
(n=9702) \\
(\%)\end{array}$ & $\begin{array}{l}\text { BIRNH } \\
(n=2561) \\
(\%)\end{array}$ & $\begin{array}{l}\text { MONICA } \\
(n=1256) \\
(\%)\end{array}$ & $\begin{array}{l}\text { BELSTRESS } \\
(n=13256) \\
(\%)\end{array}$ & $\begin{array}{l}\text { BIRNH } \\
(n=2412) \\
(\%)\end{array}$ & $\begin{array}{l}\text { MONICA } \\
(n=1228) \\
(\%)\end{array}$ & $\begin{array}{l}\text { BELSTRESS } \\
(n=3900) \\
(\%)\end{array}$ \\
\hline Smoking & 41.4 & 40.4 & 39.2 & 27.6 & 13.5 & 20.1 & 25.0 \\
\hline Obese & 9.6 & 13.4 & 17.1 & 15.2 & 19.7 & 19.0 & 17.3 \\
\hline Diabetic & 1.9 & 2.0 & 1.7 & 1.8 & 2.2 & 1.2 & 1.2 \\
\hline Region (\% south) & 19.2 & 38.3 & 41.7 & 45.3 & 38.0 & 40.4 & 58.3 \\
\hline Employed & 100 & 84.6 & 77.0 & 100 & 28.5 & 43.3 & 100 \\
\hline Hypertensive & 64.2 & 45.4 & 32.4 & 45.5 & 40.6 & 26.1 & 39.2 \\
\hline Hyperlipidaemic & 35.3 & 37.5 & 37.3 & 27.0 & 39.1 & 34.5 & 26.5 \\
\hline Angina pectoris & 5.3 & 5.2 & 3.1 & 4.9 & 7.6 & 6.0 & 10.3 \\
\hline History of acute myocardial infarction & 3.4 & 3.4 & 3.1 & 1.5 & 1.4 & 1.3 & 0.1 \\
\hline Minnesota codes $I_{1,2}$ & 1.3 & 1.8 & 1.4 & 2.0 & 0.7 & 1.2 & 0.6 \\
\hline Coronary heart disease & 8.6 & 7.9 & 5.9 & 7.5 & 8.9 & 7.7 & 10.7 \\
\hline
\end{tabular}


Multivariately adjusted odds ratios are given in table 4. These show the strength of the association between the characteristics under study and abnormal ECG findings, independently of age or the particular study involved. The significance can be deduced from the accompanying $95 \%$ confidence intervals. In contrast to the results from univariate analysis, no significant sex differential was observed for ischaemic ECG findings, mainly because there was no longer any difference in the prevalence of $\mathrm{T}$ wave abnormalities between the two sexes. In the multivariate analysis, sex differences were apparent in the prevalences of arrhyth- mias and AV block, which were both increased in men. Smoking was not associated with any of the ECG abnormalities under study, although there was a spurious (negative) association with left ventricular hypertrophy. Obese subjects were found to have an independently increased risk of having major, minor, and ischaemic ECG findings, Q/QS patterns, ST-T abnormalities, and left axis deviation. The independent effect of diabetes on abnormal ECG changes was very consistent, with increased prevalences ranging from $36-72 \%$. Regional differences between Flanders (north) and Wallonia (south) were detected in the

Table 3 Prevalences of coronary heart disease and ECG findings in 25-74 year old men and women

\begin{tabular}{|c|c|c|c|c|c|c|c|c|}
\hline & Sex & $\begin{array}{l}25-34 \\
\text { years }\end{array}$ & $\begin{array}{l}35-44 \\
\text { years }\end{array}$ & $\begin{array}{l}45-5 \\
\text { years }\end{array}$ & $\begin{array}{l}55-64 \\
\text { years }\end{array}$ & $\begin{array}{l}65-74 \\
\text { years }\end{array}$ & $\begin{array}{c}25-74 \\
\text { years }^{\star}\end{array}$ & Odds ratio (men v women) $(95 \% \mathrm{CI}) t$ \\
\hline \multirow[t]{2}{*}{ Angina pectoris } & M & $2.5 \%$ & $3.1 \%$ & $4.9 \%$ & $7.9 \%$ & $13.1 \%$ & $5.0 \%$ & $0.51(0.46$ to 0.56$)$ for age $<55$ years \\
\hline & $\mathrm{F}$ & $4.0 \%$ & $6.7 \%$ & $8.5 \%$ & $8.4 \%$ & $11.9 \%$ & $6.0 \%$ & $1.00(0.85$ to 1.18$)$ for age $\geqslant 55$ years \\
\hline \multirow{3}{*}{$\begin{array}{l}\text { History of acute myocardial } \\
\text { infarction }\end{array}$} & & & & & & & & \\
\hline & $M$ & $0.0 \%$ & $0.6 \%$ & $2.4 \%$ & $6.3 \%$ & $12.8 \%$ & $3.6 \%$ & $2.66(2.20$ to 3.22$)$ \\
\hline & $\mathrm{F}$ & $0.1 \%$ & $0.2 \%$ & $0.6 \%$ & $3.0 \%$ & $5.6 \%$ & $1.5 \%$ & \\
\hline \multirow[t]{2}{*}{ Minnesota codes $I_{1,2}$} & M & $0.4 \%$ & $0.9 \%$ & $1.7 \%$ & $3.0 \%$ & $5.0 \%$ & $1.8 \%$ & $2.02(1.63$ to 2.48$)$ \\
\hline & $\mathrm{F}$ & $0.0 \%$ & $0.4 \%$ & $0.8 \%$ & $1.6 \%$ & $3.3 \%$ & $0.9 \%$ & \\
\hline \multirow[t]{2}{*}{ Coronary heart disease } & M & $2.9 \%$ & $4.3 \%$ & $7.8 \%$ & $13.6 \%$ & $22.7 \%$ & $8.3 \%$ & $0.70(0.64$ to 0.77$)$ for age $<55$ years \\
\hline & $\mathrm{F}$ & $4.0 \%$ & $7.1 \%$ & $9.6 \%$ & $11.4 \%$ & $17.6 \%$ & $7.6 \%$ & $1.22(1.06$ to 1.39$)$ for age $\geqslant 55$ years \\
\hline \multirow[t]{2}{*}{ Major ECG findings } & M & $1.6 \%$ & $2.8 \%$ & $4.8 \%$ & $9.3 \%$ & $19.0 \%$ & $6.0 \%$ & $1.42(1.27$ to 1.57$)$ \\
\hline & $\mathrm{F}$ & $0.8 \%$ & $2.0 \%$ & $3.4 \%$ & $6.7 \%$ & $14.6 \%$ & $4.3 \%$ & \\
\hline \multirow[t]{2}{*}{ Minor ECG findings } & M & $3.4 \%$ & $5.5 \%$ & $9.2 \%$ & $16.6 \%$ & $29.4 \%$ & $10.4 \%$ & $1.13(1.05$ to 1.22$)$ \\
\hline & $\mathrm{F}$ & $3.5 \%$ & $3.9 \%$ & $8.3 \%$ & $16.1 \%$ & $29.5 \%$ & $9.5 \%$ & \\
\hline \multirow[t]{2}{*}{ Only minor ECG findings } & M & $3.3 \%$ & $5.2 \%$ & $8.5 \%$ & $14.7 \%$ & $26.3 \%$ & $9.4 \%$ & $1.10(1.01$ to 1.19$)$ \\
\hline & $\mathrm{F}$ & $3.4 \%$ & $3.6 \%$ & $7.8 \%$ & $15.0 \%$ & $28.6 \%$ & $9.1 \%$ & \\
\hline \multirow[t]{2}{*}{ Ischaemic ECG findings } & M & $2.7 \%$ & $4.3 \%$ & $7.7 \%$ & $14.6 \%$ & $26.7 \%$ & $9.0 \%$ & $0.92(0.85$ to 0.99$)$ \\
\hline & $\mathrm{F}$ & $2.8 \%$ & $3.9 \%$ & $8.2 \%$ & $16.8 \%$ & $31.3 \%$ & $9.8 \%$ & \\
\hline \multirow[t]{2}{*}{$\mathrm{Q} / \mathrm{QS}$ abnormalities } & M & $0.6 \%$ & $1.4 \%$ & $2.6 \%$ & $4.9 \%$ & $10.1 \%$ & $3.2 \%$ & $1.46(1.26$ to 1.68$)$ \\
\hline & $\mathrm{F}$ & $0.5 \%$ & $0.7 \%$ & $1.9 \%$ & $3.7 \%$ & $8.2 \%$ & $2.3 \%$ & \\
\hline \multirow[t]{2}{*}{ ST abnormalities } & M & $0.2 \%$ & $0.4 \%$ & $1.2 \%$ & $3.4 \%$ & $9.0 \%$ & $2.3 \%$ & 0.75 (0.65 to 0.88$)$ \\
\hline & $\mathrm{F}$ & $0.4 \%$ & $0.8 \%$ & $1.8 \%$ & $4.3 \%$ & $9.3 \%$ & $2.6 \%$ & \\
\hline \multirow[t]{2}{*}{$\mathrm{T}$ abnormalities } & M & $2.0 \%$ & $2.9 \%$ & $5.3 \%$ & $10.7 \%$ & $19.8 \%$ & $6.5 \%$ & $0.86(0.79$ to 0.93$)$ \\
\hline & $\mathrm{F}$ & $2.2 \%$ & $2.8 \%$ & $6.1 \%$ & $13.4 \%$ & $24.1 \%$ & $7.6 \%$ & \\
\hline \multirow[t]{2}{*}{ Arrhythmias } & M & $0.4 \%$ & $0.4 \%$ & $0.7 \%$ & $1.6 \%$ & $4.8 \%$ & $1.2 \%$ & $1.18(0.93$ to 1.49$)$ \\
\hline & $\mathrm{F}$ & $0.3 \%$ & $0.4 \%$ & $0.5 \%$ & $1.3 \%$ & $3.6 \%$ & $1.0 \%$ & \\
\hline \multirow[t]{2}{*}{ AV block } & M & $0.1 \%$ & $0.1 \%$ & $0.1 \%$ & $0.1 \%$ & $0.3 \%$ & $0.2 \%$ & $2.00(0.89$ to 4.49$)$ \\
\hline & $\mathrm{F}$ & $0.1 \%$ & $0.1 \%$ & $0.1 \%$ & $0.0 \%$ & $0.1 \%$ & $0.1 \%$ & \\
\hline \multirow[t]{2}{*}{ High $\mathrm{R}$ wave } & M & $6.3 \%$ & $3.8 \%$ & $3.4 \%$ & $3.8 \%$ & $6.6 \%$ & $3.2 \%$ & $6.56(5.06$ to 8.50$)$ for age $<55$ years \\
\hline & $\mathrm{F}$ & $0.5 \%$ & $0.5 \%$ & $0.8 \%$ & $2.5 \%$ & $3.9 \%$ & $1.3 \%$ & 1.63 (1.25 to 2.11$)$ for age $\geqslant 55$ years \\
\hline \multirow[t]{2}{*}{ Left ventricular hypertrophy } & M & $0.4 \%$ & $0.2 \%$ & $0.4 \%$ & $0.7 \%$ & $2.7 \%$ & $0.7 \%$ & $1.62(1.14$ to 2.31$)$ \\
\hline & $\mathrm{F}$ & $0.1 \%$ & $0.1 \%$ & $0.1 \%$ & $0.8 \%$ & $1.8 \%$ & $0.5 \%$ & \\
\hline \multirow[t]{2}{*}{ Left axis deviation } & M & $1.4 \%$ & $2.9 \%$ & $4.6 \%$ & $7.5 \%$ & $12.8 \%$ & $4.8 \%$ & $1.96(1.73$ to 2.23$)$ \\
\hline & $\mathrm{F}$ & $0.9 \%$ & $1.3 \%$ & $2.5 \%$ & $3.9 \%$ & $7.7 \%$ & $2.5 \%$ & \\
\hline \multirow[t]{2}{*}{ Arrhythmias or AV block } & M & $0.5 \%$ & $0.5 \%$ & $0.8 \%$ & $1.7 \%$ & $5.1 \%$ & $1.3 \%$ & $1.22(0.97$ to 1.53$)$ \\
\hline & $\mathrm{F}$ & $0.4 \%$ & $0.5 \%$ & $0.6 \%$ & $1.3 \%$ & $3.8 \%$ & $1.1 \%$ & \\
\hline \multirow[t]{2}{*}{ Bundle branch block } & $M$ & $0.4 \%$ & $0.7 \%$ & $1.2 \%$ & $2.4 \%$ & $5.4 \%$ & $1.6 \%$ & 2.15 (1.69 to 2.73$)$ \\
\hline & $\mathrm{F}$ & $0.2 \%$ & $0.2 \%$ & $0.5 \%$ & $1.2 \%$ & $3.2 \%$ & $0.8 \%$ & \\
\hline \multirow[t]{2}{*}{ Left bundle branch block } & M & $0.1 \%$ & $0.2 \%$ & $0.3 \%$ & $0.8 \%$ & $2.0 \%$ & $0.5 \%$ & $1.09(0.77$ to 1.55$)$ \\
\hline & $\mathrm{F}$ & $0.0 \%$ & $0.1 \%$ & $0.2 \%$ & $0.8 \%$ & $1.7 \%$ & $0.5 \%$ & \\
\hline \multirow[t]{2}{*}{ Right bundle branch block } & M & $0.4 \%$ & $0.5 \%$ & $0.9 \%$ & $1.5 \%$ & $3.3 \%$ & $1.1 \%$ & 3.45 (2.43 to 4.89$)$ \\
\hline & $\mathrm{F}$ & $0.2 \%$ & $0.1 \%$ & $0.2 \%$ & $0.4 \%$ & $1.5 \%$ & $0.4 \%$ & \\
\hline \multirow[t]{2}{*}{ Wolff-Parkinson-White } & M & $0.06 \%$ & $0.13 \%$ & $0.07 \%$ & $0.09 \%$ & $0.31 \%$ & $0.11 \%$ & $2.78(1.08$ to 7.19$)$ \\
\hline & $\mathrm{F}$ & $0.13 \%$ & $0.02 \%$ & $0.05 \%$ & $0.00 \%$ & $0.00 \%$ & $0.04 \%$ & \\
\hline \multirow[t]{2}{*}{ Atrial fibrillation/flutter } & $M$ & $0.06 \%$ & $0.04 \%$ & $0.21 \%$ & $0.58 \%$ & $2.70 \%$ & $0.55 \%$ & $1.81(1.14$ to 2.89$)$ \\
\hline & $\mathrm{F}$ & $0.00 \%$ & $0.07 \%$ & $0.08 \%$ & $0.32 \%$ & $1.53 \%$ & $0.33 \%$ & \\
\hline
\end{tabular}

^Age standardised.

†Age adjusted according to logistic regression analysis. 
๙ิ

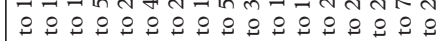

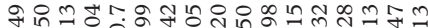

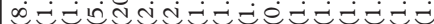

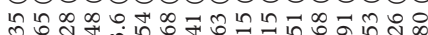
-

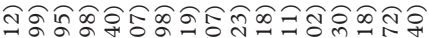

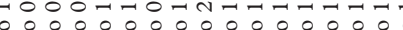

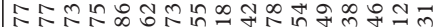

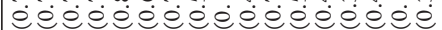

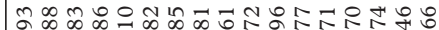
- 0 -

ลकㅎำ

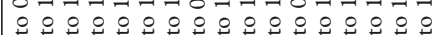

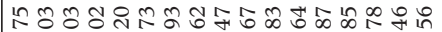

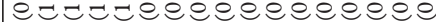

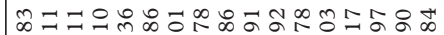

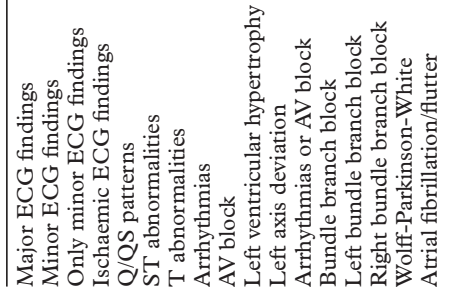

prevalences of major ECG findings and arrhythmias, which were higher in the north, and minor, ischaemic, and Q wave abnormalities, which were higher in the south. Being currently employed was associated with a lower prevalence of minor and $\mathrm{T}$ wave abnormalities and consequently with a lower prevalence of ischaemic ECG findings. Finally, as expected, prevalent coronary heart disease was strongly related to all ECG findings under study, especially with major ECG findings, ST-T changes, $\mathrm{Q} / \mathrm{QS}$ patterns, AV block, and the WolffParkinson-White syndrome, all abnormalities being at least twice as common among subjects with overt coronary heart disease.

\section{Discussion}

The ECG has been widely described in medical reports as a useful diagnostic tool for assessing "silent" heart disease. Many epidemiological studies have shown the association between ECG findings and subsequent coronary and cardiovascular disease and mortality. ${ }^{3-15}$ The use of ECGs in epidemiological research has been greatly facilitated by the introduction of the Minnesota code classification system. ${ }^{16}{ }^{17}$ There are several reports from different populations on the prevalence of ECG abnormalities determined on the basis of the Minnesota coding criteria. ${ }^{18-24}$ In general, the observed prevalences in our large sample of Belgian men and women are in line with what might be expected from a western European country.

INTERPRETATION OF PREVALENCE REPORTING In comparing the results of our study with those obtained from other samples, one should take into account that our sample is population based, with varying participation rates between the four projects but with no exclusions. Some investigators have reported the results of prevalence studies in a subcohort of subjects free of symptomatic coronary heart disease. Moreover, most studies on the prevalence of abnormal ECG changes have been carried out in men only, and few studies have also sampled women. In other studies showing the prevalence of ECG changes, the age range is often more limited than our range of 25-74 years, and is usually restricted to 45-64 years. Because of the strong age dependency of ECG changes, any study comparing prevalences of ECG abnormalities should take this into account. As reported by several other investigators, there are also important ethnic differences among individuals free of coronary heart disease in the occurrence of abnormalities on the resting ECG. In a recent paper from the ARIC (atherosclerosis risk in communities) study, ${ }^{23}$ Vitelli and colleagues confirmed findings from previous studies ${ }^{12}$ that racial differences in the prevalences of both major and minor ECG changes between adult black and white Americans are not entirely explained by differences in established coronary heart disease risk factors. In international projects such as the seven countries study ${ }^{19}$ and the study by the International Collaborative Group, ${ }^{35}$ the 
lowest prevalence rates of ECG abnormalities are consistently found in Eastern populations, independently of other coronary heart disease risk factors.

MAJOR, MINOR, AND ISCHAEMIA-LIKE ECG CHANGES

Our definitions of major and minor ECG abnormalities are based on those in the pooling project. ${ }^{32}$ In that study of 7076 middle aged men free of coronary heart disease, the prevalences were $3.8 \%$ for major and $9.0 \%$ for minor ECG abnormalities, respectively. In our study involving four Belgian databases, the age standardised prevalences of major ECG findings were $6.0 \%$ in men and $4.3 \%$ in women, these rates being significantly different. In the western European groups involved in the International Collaborative Group, ${ }^{35}$ the prevalence rates of these major ECG changes in men in the age group 40-59 years ranged from about $4.0 \%$ in the French, Italian, and Irish samples, up to $7.3 \%$ in Denmark and $8.3 \%$ in Finland. In two US projects, the Charleston heart study ${ }^{12}$ and the Evans County heart study, ${ }^{9}$ the prevalence of major ECG findings in middle aged men free of coronary heart disease was about $7 \%$. The highest prevalences in both men and women were observed in the Chicago Heart Association detection project in industry ${ }^{11}$ where major ECG changes occurred in $9.6 \%$ of men and in $12.9 \%$ of women aged 40-64 years and free of symptomatic coronary heart disease. In contrast, the prevalence of minor ECG abnormalities in that study was rather low $(7.3 \%$ in men and $4.5 \%$ in women). In the different studies using the pooling project definition ${ }^{32}$ of minor ECG abnormalities, very heterogeneous results were obtained for prevalence, mainly because of observer bias, as personal interpretation is more likely to play a part in the coding of less clinically relevant ECG findings. In the male participants of the Evans County heart study ${ }^{9}$ (aged 40-64 years) and the ARIC study ${ }^{23}$ (aged 45-64 years), the prevalence of minor ECG codes was exceptionally high $(23.7 \%$ and $25.2 \%$, respectively), while that in the Charleston heart study $^{12}(13.2 \%)$ was comparable with those found in working men aged $40-55$ years in the Chicago Western Electric Company study $(11.2 \%)$ and in the participants in the Honolulu heart program ${ }^{10}$ in men of Japanese ancestry aged 45-68 years (10.0\%). Apart from these US studies, we found no other papers showing prevalence rates of minor ECG codes. From our large Belgian database, we can conclude that about the same proportion of men and women from the general population aged 25-74 years show minor changes on their resting ECG (without any major ECG findings), namely $9.4 \%$ and $9.1 \%$, the difference being only of borderline significance.

Apart from the observed age and sex effects on the prevalences of major and minor ECG changes in our database, we also found significant associations with obesity, diabetes, prevalent coronary heart disease, and to a lesser extent region and employment status, while only smoking was unrelated. The absence of an effect of tobacco consumption is in agreement with the results of three different US studies, ${ }^{91236}$ while the positive association with body mass index was observed in only one of those studies. ${ }^{9}$ The strong impact of diabetes found in our study was confirmed in the Charleston heart study alone, ${ }^{12}$ which involved only men.

ISCHAEMIA-LIKE ECG CHANGES

Q wave patterns, ST segment depression or elevation, $\mathrm{T}$ wave inversion or flattening, and left bundle branch block are often seen as indications of silent myocardial ischaemia. The results from different studies are quite consistent, in that ischaemia-like ECG changes are associated with an approximately twofold increased risk of dying of coronary heart disease..$^{15}{ }^{37}$ In our combined samples, prevalence rates were $9.0 \%$ and $9.8 \%$ in men and women, respectively. These rates are comparable with those reported from other western European studies (Renfrew and Paisley survey, ${ }^{14}$ Scottish heart health study ${ }^{22}$ ) and some US studies (the Framingham study, ${ }^{38}$ Chicago Heart Association detection project in indus$\left.\operatorname{try}^{39}\right)$. In two older studies on men only-the Seven Countries studies ${ }^{4}$ (40-59 years) and the Whitehall study ${ }^{5}$ (40-64 years)-prevalences of ischaemia-like ECG findings were $6.4 \%$ and $6.2 \%$, respectively, which again, when taking into account the steep trend in prevalence after the age of 65, are comparable with our figures.

With respect to the influence of lifestyle characteristics on the prevalence of ischaemialike ECG changes, significant associations were observed not only for age and overt coronary heart disease, but also for obesity, diabetes, region, and employment status. We found no other reports showing the impact of these latter characteristics on ischaemia-like or ST-T type abnormalities.

\section{SEPARATE ECG CODES}

Q/QS findings are often seen in subjects with previous myocardial infarction and are regarded in asymptomatic individuals as possible indicators of myocardial ischaemia. In our study, such $\mathrm{Q} / \mathrm{QS}$ changes were observed in $3.2 \%$ of all men and $2.3 \%$ of all women. The prevalence was strongly age dependent and the adjusted sex ratio was about 2 . With respect to the different age criteria used in several studies, and taking into account the steep age gradient after the age of 60 , our results are in agreement with those found in other published reports. In a report on six large European cohorts, ${ }^{20}$ Rose and colleagues found homogeneity in the prevalence of $\mathrm{Q} / \mathrm{QS}$ findings among populations, with prevalences varying between 3.4$5.5 \%$ in men aged $40-59$ years. In the Whitehall study, ${ }^{5} 2.7 \%$ of men aged $40-64$ years showed $\mathrm{Q} / \mathrm{QS}$ wave changes on their resting ECG, while these occurred in $4.2 \%$ of male participants (aged 40-59 years) from the British regional heart study. ${ }^{8}$ Finally, two US studies also included women in their population sample. The Framingham study ${ }^{21}$ reported Minnesota code $\mathrm{I}_{1-3}$ prevalences of $2.1 \%$ in men and $1.7 \%$ in women, both sexes being in 
the age range $30-62$ years. The sex ratio of 2 , as observed by us, is in line with the results from the 45-64 years old white participants of the ARIC study, ${ }^{23}$ in which prevalences were $2.0 \%$ in men and $0.6 \%$ in women. Apart from the established associations with age, sex, and prevalent coronary heart disease, we found no reports dealing with the influence of lifestyle related characteristics on the occurrence of $\mathrm{Q} / \mathrm{QS}$ codes. We observed more $\mathrm{Q} / \mathrm{QS}$ findings among subjects with diabetes $(+54 \%)$ and obesity $(+42 \%)$, and in participants from the French speaking community $(+36 \%)$. No significant relation with smoking behaviour was seen.

As it represents a shift in the electrical axis of the heart, left axis deviation is usually considered to be an indication of left anterior hemiblock. In men, the prevalence found in published reports varies from $3.1 \%$ in both the Whitehall study ${ }^{5}$ (40-64 years) and the Framingham study ${ }^{21}$ (30-62 years) to $6.4 \%$ in the Australian Busselton study (40-79 years). The reported proportion of women with left axis deviation on their ECG varies from $1.6 \%$ in a Croatian study ${ }^{40}(35-54$ years) to $3.9 \%$ in the Busselton study. ${ }^{7}$ In all these studies, a strong age dependency was shown, and prevalences in men were about twofold higher than in women. Our results are in agreement with these observations, with prevalences of $4.8 \%$ in men and $2.5 \%$ in women, the adjusted sex ratio being 2 . Apart from the influence of age and sex, a positive association with obesity was seen $(+33 \%)$, while the effect of overt coronary heart disease $(+15 \%)$ was, surprisingly, only of borderline significance.

The definition for left ventricular hypertrophy in our study was the joint occurrence of high $\mathrm{R}$ waves and ST-T type abnormalities. Many criteria for an ECG definition of left ventricular hypertrophy have been suggested, most of which have high specificity but low sensitivity. ${ }^{41-43}$ In clinical practice and epidemiological research, tall $\mathrm{R}$ waves have often been associated with a diagnosis of left ventricular hypertrophy, though when accompanied by ST segment depression and $\mathrm{T}$ wave inversion this feature has been shown to be a more powerful risk factor for the development of coronary artery disease. ${ }^{44}$ Framingham data ${ }^{46}$ showed that the estimated prevalence of left ventricular hypertrophy, as defined above, increased from $0.6 \%$ in 40 year old men to $5.5 \%$ in 70 year old men. In women, the prevalence was about half that in men at virtually all ages. In the white male cohort of the Charleston heart study ${ }^{12}$ aged $35-74$ years, the prevalence of left ventricular hypertrophy was $0.9 \%$, while in the Honolulu heart program ${ }^{10}$ in men aged 45-64 years, the prevalence was $0.6 \%$. In our study the prevalence of left ventricular hypertrophy on ECG was estimated to be $0.7 \%$ in men and $0.5 \%$ in women, with a sex ratio of 2.21 after multivariate adjustment. No significant excess was found in obese subjects, while smoking was negatively related to ECG evidence of left ventricular hypertrophy. This unexpected finding is in line with observations made in the LIFE (losartan inter- vention for endpoint reduction in hypertension) study. ${ }^{47}$ In this sample of hypertensive patients with electrocardiographically detected left ventricular hypertrophy, many fewer current smokers $(<17 \%)$ were represented compared with the general population. A possible explanation may be the fact that electrocardiography has a lower sensitivity for the diagnosis of left ventricular hypertrophy in smokers than in non-smokers. From the PIUMA (Progetto ipertensione umbria monitoraggio ambulatoriale) study ${ }^{48}$ it was concluded that in hypertensive smokers the sensitivity of the ECG is lower than in non-smokers when using peripheral or left precordial voltage criteria, probably owing to increased chest size in smokers resulting from increased lung compliance.

Many epidemiological papers have considered ST abnormalities and T wave changes in the general population. As in most of these the definitions also include the less stringent codes $\mathrm{IV}_{3-4}$ and $\mathrm{V}_{3-4}$, which are more subject to personal interpretation; large variation is observed in the published prevalence data. In a comparison of several European cohorts ${ }^{20}$ consisting of 40-59 year old men, Rose and colleagues reported prevalences of ST segment depression $\left(\mathrm{IV}_{1-3}\right)$ of the order of $2.6 \%$ to $3.6 \%$, while for $\mathrm{T}$ wave abnormalities $\left(\mathrm{V}_{1-3}\right)$ prevalence rates were between $3.4 \%$ and $5.9 \%$. In the Australian Busselton study ${ }^{7}$ (40-79 years), prevalence rates of ST and $\mathrm{T}$ wave changes were $2.4 \%$ and $6.8 \%$ in women and $0.5 \%$ and $4.6 \%$ in men, respectively. These differences between sexes are in agreement with data published by Ostrander and associates in an early paper on ECG findings in about 5000 men and women aged 16 to over 80 years, with ST changes occurring in $5.4 \%$ of women and in $2.5 \%$ of men, while $\mathrm{T}$ wave abnormalities were found in $11.6 \%$ of men and $13.1 \%$ of women. ${ }^{18}$ The magnitude of the sex difference was, however, not confirmed by data from the Framingham study ${ }^{38}$ in $44-74$ year old subjects, where prevalences of ST and $\mathrm{T}$ wave changes were, respectively, $7.7 \%$ and $11.0 \%$ in women, and $6.9 \%$ and $12.8 \%$ in men. The results of our study support their findings, in that men and women from the general population did not differ much with regard to the occurrence of ST changes $(2.6 \%$ in women, $2.3 \%$ in men) and $\mathrm{T}$ wave abnormalities $(7.6 \%$ in women, $6.5 \%$ in men). Concerning lifestyle characteristics, we found no other reports confirming our findings of higher prevalences of ST and T wave changes among diabetics and obese persons.

There is little information in epidemiological reports on the prevalence of signs of impaired atrioventricular conduction (AV block) on the resting ECG. In a large sample of over 100000 aircrew men aged $16-50$ years, Hiss and $\mathrm{Lamb}^{24}$ found AV block in $0.6 \%$ of the ECGs, while in the Framingham study, ${ }^{3}$ prevalences in 30-62 year old men and women were, respectively, $0.7 \%$ and $0.8 \%$. The reason why these figures are higher than those observed in our study $(0.2 \%$ in men, $0.1 \%$ in women $)$ is unclear. Only seven of the 18403 middle aged men participating in the Whitehall study ${ }^{5}$ had 
complete or second degree AV block or WolffParkinson-White syndrome. The latter occurred in four of these seven men. Apart from a significant association with sex, we observed 2.6 times more AV block in subjects suffering from coronary heart disease. No significant age gradient in prevalence of AV block was observed. The prevalence of the WolffParkinson-White syndrome in our combined sample was $0.11 \%$ in men and $0.04 \%$ in women. This syndrome occurred significantly more often in men and in subjects with a history of coronary heart disease. In the large sample of male US aircrew personnel, ${ }^{24}$ the prevalence of the Wolff-Parkinson-White syndrome was about $0.2 \%$.

In contrast to AV block, we found many epidemiological studies dealing with bundle branch block, though again mostly in men. ${ }^{3-}$ 591013 The reported prevalences of Minnesota codes VII $_{1,2,4}$ in men range from $1.2 \%$ in the Framingham study ${ }^{3}$ (30-62 years) up to $2.7 \%$ in the white men from the Evans County heart study $^{9}$ (40-64 years). In our study, the observed prevalences of bundle branch block were $1.6 \%$ in men and $0.8 \%$ in women, the adjusted sex ratio being 2.28. This sex differential was entirely attributable to a difference in the prevalence of right bundle branch block (sex ratio $=3.51$ ). The prevalence of left bundle branch block was similar in the two sexes. Our results are comparable with those obtained in the Reykjavik study, ${ }^{49}$ in which a significant sex differential in the prevalence of right bundle branch block was also observed (sex ratio $=2.1)$. The sex ratios in the Framingham study ${ }^{50}$ were 1.6 for left bundle branch block and 3.0 for right bundle branch block. With respect to lifestyle characteristics, only age, sex, and a history of coronary heart disease were related to bundle branch block in our study, these results again being consistent with observations from the Framingham study.

In relation to arrhythmias, most reports have focused on atrial fibrillation and flutter, two types of atrial arrhythmia with the same aetiological background. Earlier observations from the seven countries study ${ }^{4}$ were recently confirmed by data from the Framingham study ${ }^{51}$ and the Paris prospective study, ${ }^{52}$ in that persons with idiopathic atrial fibrillation but no clinically apparent disease had an increased mortality risk. In the Whitehall study, ${ }^{5}$ atrial fibrillation was seen in 4/1000 men. There was a steep age gradient and about half the subjects reported a history of coronary heart disease. Similar prevalences of Minnesota code $\mathrm{VIII}_{3}$ in men were observed in the Evans County heart $\operatorname{study}^{9}(0.4 \%)$, the Busselton study ${ }^{7}(0.2 \%)$, the British regional heart study ${ }^{13}(0.7 \%)$, and the Paris prospective study ${ }^{52}(0.5 \%)$. Based on incidence data from the Framingham study, ${ }^{53}$ men had a 1.5 times greater risk for developing atrial fibrillation than women. Other risk factors for the development of atrial fibrillation were age, diabetes, hypertension, congestive heart failure, valve disease, and a history of myocardial infarction. In our study, we found prevalences of $0.55 \%$ in men and $0.33 \%$ in women, the adjusted sex ratio being 2.27 . This prevalence was found to be significantly increased in older people and in those with diabetes and overt coronary heart disease.

CONCLUSIONS

This pooling of four large epidemiological studies provides us with accurate estimates of the prevalence of several electrocardiographic findings in adult men and women from the general population. Our findings agree, in general, with what would be expected for a typical western European population. Most prevalences increase exponentially with age and are greater among people with diabetes, obesity, and a history of coronary heart disease. Smoking behaviour seems unrelated to any ECG features except for a negative association with the occurrence of left ventricular hypertrophy. This paper is one of the few that have reported prevalences of ECG findings in women as well as men. Compared with men, women tend to have fewer abnormalities on the resting ECG.

1 Fye WB. A history of the origin, evolution, and impact of electrocardiography. Am f Cardiol 1994;73:937-49.

2 Sox HC, Garber AM, Littenberg B. The resting electrocardiogram as a screening test. A clinical analysis. Ann Intern Med 1989;111:489-502.

3 Higgins IT, Kannel WB, Dawber TR. The electrocardiogram in epidemiological studies: reproducibility, validity and international comparison. Br F Prev Soc Med 1965;19. 53-68.

4 Blackburn H, Taylor HL, Keys A. The electrocardiogram in prediction of five-year coronary heart disease incidence among men aged 40 through 59. Circulation 1970; 42(suppl): $154-61$.

5 Rose GA, Baxter PJ, Reid DD, et al. Prevalence and prognosis of electrocardiographic findings in middle-aged men. $\mathrm{Br}$ sis of electrocardiographic

6 Cedres BL, Liu K, Stamler J, et al. Independent contribution of electrocardiographic abnormalities to risk of death from coronary heart disease, cardiovascular diseases and all causes. Findings of three Chicago epidemiologic studies. Circulation 1982;65:146-53.

7 Cullen K, Stenhouse NS, Wearne KL, et al. Electrocardiograms and 13-year cardiovascular mortality in the Busselton study. Br Heart J 1982;47:209-12.

8 Macfarlane PW. British Regional Heart Study: the electrocardiogram and risk of myocardial infarction on follow-up. f Electrocardiol 1987;20(suppl.):53-6.

9 Strogatz DS, Tyroler HA, Watkins LO, et al. Electrocardiographic abnormalities and mortality among middle-aged black and white men of Evans county, Georgia. 7 Chronic Dis 1987;40:149-55.

10 Knutsen R, Knutsen SF, Curb D, et al. The predictive value of resting electrocardiograms for 12-year incidence of coronary heart disease in the Honolulu Heart Program. F Clin Epidemiol 1988;41:293-302.

11 Liao Y, Liu K, Dyer A, et al. Major and minor electrocardiographic abnormalities and risk of death from coronary heart disease, cardiovascular diseases and all causes in men and women. 7 Am Coll Cardiol 1988;12:1494-500.

12 Sutherland SE, Gazes PC, Keil JE, et al. Electrocardiographic abnormalities and 30-year mortality among white and black men of the Charleston Heart study. Circulation 1993;88:2685-92.

13 Whincup PH, Wannamethee G, Macfarlane PW, et al. Resting electrocardiogram and risk of coronary heart disease in middle-aged British men. $f$ Cardiovasc Risk 1995;2:53343.

14 Hart CL, Watt GCM, Davey Smith G, et al. Pre-existing ischaemic heart disease and ischaemic heart disease
mortality in women compared with men. Int $\mathcal{f}$ Epidemiol mortality in wom

15 De Bacquer D, De Backer G, Kornitzer M, et al. Prognostic value of ECG findings for total, cardiovascular disease, and coronary heart disease death in men and women. Heart 1998;80:570-7.

16 Blackburn H, Keys A, Simonson E, et al. The electrocardiogram in population studies. A classification system. Circulation 1960;21:1160-75.

17 Blackburn H. Electrocardiographic classification for population comparisons. The Minnesota code. 7 Electrocardiol 1969;2:5-9.

18 Ostrander LD, Brandt RL, Kjelsberg MO, et al. Electrocardiographic findings among the adult population of a total natural community. Tecumseh, Michigan. Circulation 1965; 31:888-98.

19 Keys A, Aravanis C, Blackburn HW, et al. Epidemiological studies related to coronary heart disease: characteristics of
men aged 40-59 in seven countries. Acta Med Scand Suppl men aged 40-59 
20 Rose GA, Ahmeteli M, Checcacci L, et al. Ischaemic heart disease in middle-aged men. Prevalence comparisons in disease in middle-aged men. Preval
Europe. Bull WHO 1968;38:885-95.

21 Shurtleff D. Some characteristics related to the incidence of cardiovascular disease and death: Framingham study, 18 year follow-up. Section 30. In: Kannel WB, Gordon T, eds. The Framingham study - an epidemiological investigation of cardiovascular disease. Washington DC: US DHEW, USPHS, NIH, DHEW publication (NIH) 74-599, Feb 1974.

22 Smith WC, Kenicer MB, Tunstall-Pedoe H, et al. Prevalence of coronary heart disease in Scotland: Scottish Heart Health Study. Br Heart ₹ 1990;64:295-8.

23 Vitelli LL, Crow RS, Shahar E, et al. Electrocardiographic findings in a healthy biracial population. Atherosclerosis Risk in Communities (ARIC) Study Investigators. $A m \mathcal{F}$ Cardiol 1998;81:453-9.

24 Hiss RG, Lamb LE. Electrocardiographic findings in 122,043 individuals. Circulation 1962;25:947-61.

25 Kornitzer M, De Backer G, Dramaix M, et al. The Belgian heart disease prevention project. Modification of the heart disease prevention project. Modification of the coronary risk pro

26 WHO European Collaborative Group. An international controlled trial in the multifactorial prevention of coronary heart disease. Int $\mathcal{F}$ Epidemiol 1975;3:219-24.

27 De Backer G. Nutrition and health: an interuniversity study. Regional differences in dietary habits, coronary risk factor and mortality rates in Belgium. I. Design and methodology. Acta Cardiol 1984;39:285-92.

28 WHO-MONICA Project Principal Investigators. The World Health Organisation MONICA project (Monitoring Trends and Determinants in Cardiovascular Disease): a major international collaboration. $\mathcal{F}$ Clin Epidemiol 1988; 41:105-14.

29 De Henauw S, De Backer G. Primary results from the MONICA Ghent-Charleroi study. Arch Publ Health 1991;49:225-39.

30 Houtman, M Kornitzer, P De Smet, et al. Job stress, absenteeism and coronary heart disease European cooperative teeism and coronary heart disease European cooperative study (the JACE study). Design of a multicen

31 Rose GA, Blackburn H, Gillum RF, et al. Cardiovascular survey methods. WHO Monograph Series 56, 2nd ed. Geneva: WHO, 1982

32 The Pooling Project Research Group. Relationship of blood pressure, serum cholesterol, smoking habits, relative weigh and ECG abnormalities to incidence of major coronary events: final report of the Pooling Project. $\mathcal{f}$ Chronic Dis 1978;31:201-306.

33 Rothman K. Modern epidemiology. Boston: Little, Brown and Co, 1986.

34 The SAS system for Windows, release 6.11. Cary, NC: SAS Institute Inc.

35 International Collaborative Group. Joint discussion on "Relationship of glucose tolerance to prevalence of ECG abnormalities and to 5 -year mortality from cardiovascular disease." f Chronic Dis 1979;32:829-37.

36 Stamler R, Stamler J, Schoenberger JA, et al. Relationship of glucose tolerance to prevalence of ECG abnormalities and glucose tolerance to prevalence of ECG abnormalities and the Chicago Heart Association Detection Project in Industhe Chicago Heart Association Dete
37 De Bacquer D, De Backer G, Kornitzer M, et al. Prognostic value of ischaemic electrocardiographic findings for cardiovascular mortality in men and women. $7 \mathrm{Am} \mathrm{Coll} \mathrm{Cardiol}$ 998;32:680-5.

38 Kannel WB, Anderson K, McGee DL, et al. Non-specific electrocardiographic abnormality as a predictor of coronary heart disease: the Framingham Heart Study. Am Heart f 1987;113:370-6.

39 Liao Y, Liu K, Dyer A, et al. Sex differential in the relationship of electrocardiographic ST-T abnormalities to risk of coronary death: 11.5 year follow-up findings of the Chicago Heart Association Detection Project in Industry. Circulation 1987;75:347-52.

40 Durakovic Z, Mimica M. Left axis deviation and tall R waves in the electrocardiogram. F Electrocardiol 1981;14: 31-7.

41 Kannel WB. Left ventricular hypertrophy as a risk factor: the Framingham experience. F Hypertens Suppl 1991;9:S39.

42 Post WS, Levy D. New developments in the epidemiology of eft ventricular hypertrophy. Curr Opin Cardiol 1994;9:53441.

43 Levy D, Labib SB, Anderson KM, et al. Determinants of sensitivity and specificity of electrocardiographic criteria for left ventricular hypertrophy. Circulation 1990;81:81520 .

44 Kannel WB, Gordon T, Castelli WP, et al. Electrocardiographic left ventricular hypertrophy and risk of coronary . The Framingham study Ann Intern Med 1970;72:813-22.

45 Kannel WB. Prevalence and natural history of electrocardiographic left ventricular hypertrophy. Symposium on $\mathrm{LVH}$ in essential hypertension. Am $\mathcal{F}$ Med (special issue), 1983

46 Kannel WB, Gordon T, Offutt D. Left ventricular hypertrophy by electrocardiogram: prevalence, incidence, and mortality in the Framingham study. Ann Intern Med 1969;71: 89-105.

47 Dahlof B, Devereux RB, Julius S, et al. Characteristics of 9194 patients with left ventricular hypertrophy: the LIFE study. Losartan Intervention For Endpoint Reduction in study. Losartan Intervention For Endpoint

48 Schillaci G, Verdecchia P, Sacchi N, et al. Influence of cigarette smoking on the electrocardiographic diagnosis of left ventricular hypertrophy in arterial hypertension. G Ital Cardiol 1999;29:34-8

49 Thrainsdottir IS, Hardarson T, Thorgeirsson G, et al. The epidemiology of right bundle branch block and its association with cardiovascular morbidity-the Reykjavik Study. Eur Heart f 1993;14:1590-6.

50 Schneider JF, Thomas HE, Kreger BE, et al. Newly acquired right bundle branch block: the Framingham study. Ann Intern Med 1980;92:37-44.

51 Benjamin EJ, Wolf PA, D'Agostino RB, et al. Impact of atrial fibrillation on the risk of death: the Framingham Heart Study. Circulation 1998;98:946-52.

52 Jouven X, Desnos M, Guerot C, et al. Idiopathic atrial fibrillation as a risk factor for mortality. The Paris Prospective Study I. Eur Heart 7 1999;20:896-9.

53 Benjamin EJ, Levy D, Vaziri SM, et al. Independent risk factors for atrial fibrillation in a population-based cohort. The Framingham Heart Study. $\mathscr{F} A M A$ 1994;271:840-4. 